\title{
Recall of individual CCC trigrams over short intervals of time as a function of mode of presentation
}

\author{
RICHARD K. COOLEY AND JOHN A. MCNULTY \\ DALHOUSIE UNIVERSITY
}

\begin{abstract}
A number of CCC trigrams were presented one at a time to Ss over a period of four days. Using Peterson and Peterson's technique, recall of the items was tested after varying retention intervals. On each day half of the trigrams were presented aurally and the other half visually. Results of the study showed that recall following short retention intervals was better when the mode of presentation was auditory. At longer intervals recall either tended to be better when the items were presented visually or did not differ between the two modes of presentation.
\end{abstract}

Recent evidence suggests that when a stimulus array is encoded, it is held in short-term memory by means of an auditory code (Conrad, 1964; Sperling, 1963; Turvey, 1966; Wickelgren, 1963). A visually presented stimulus array is thought to be stored initially in a visual information storage (VIS), the contents of which can become available to other parts of the memory system through a "scanning" or "read-out" procedure. When rehearsal of this information occurs, it is recoded and becomes part of a more permanent auditory information storage (AIS), with rehearsal being essentially auditory rehearsal (Sperling, 1963; Turvey, 1966).

Murdock (1966) has argued that if information can be retrieved either from sensory stores (such as the VIS) or from more "organized" parts of the memory system (such as the AIS), then recall over short intervals of time should vary with the mode of presentation used. Using his probe technique with paired associates, Murdock (1966) found a greater recency effect with auditory presentation and a more pronounced primacy effect with visual presentation. Similarly, although input modality had a negligible effect upon overall performance, Schulz \& Hopkins (in press) observed in free learning a more pronounced recency effect under auditory than under visual conditions. Since both of these studies employed lists of items as learning materials, it could be that the observed interaction of modality with retention interval (or, in the case of these two studies, input position of the recalled item) was due in some way to interference effects from other items in the list operating differentially in the two modes of presentation.

The present study was an attempt to determine whether the interaction would be obtained when the potential effects of this intralist interference were minimized. Peterson \& Peterson's (1959) technique was used so that no other learning items would in- tervene between the presentation of any item and its recall, thereby minimizing intralist interference. Because of the important role that rehearsal is thought to play in the recoding of information, another advantage of the method was that it was designed to minimize rehearsal.

\section{Method}

Subjects. Ten women taking an introductory course in experimental psychology were used as Ss. Each was run for four consecutive daily sessions of approximately $1 \mathrm{~h}$ duration each. They were paid $2.00 /$ $\mathrm{h}$ for participating in the experiment.

Materials and Apparatus. 192 CCC trigrams of from 0 to $33 \%$ association value were taken from Underwood \& Schulz's tables (1960, Appendix B, pp. 319-329). They were randomly broken into eight sets of 24 items each.

For visual presentation, the elght sets were typed on white memory drum paper in capital letters. Within each set, the 24 items were randomly ordered with the restriction that no two successive items have any letters in common. The trigrams were presented on a memory drum at the rate of $1.5 \mathrm{sec}$ per trigram.

For auditory presentation, the eight sets were tape recorded in a male voice one letter at a time to the rhythm of a metronome beating twice per sec, i.e., one letter spoken every $0.5 \mathrm{sec}$. This meant that the presentation time for each trigram was $1.5 \mathrm{sec}$, the same stimulus duration as that used for visual presentation. The 24 items within each set were again randomly ordered with the same restriction as before. The trigrams were presented on a tape recorder through headphones. Binaural presentation was used.

Procedure. During each daily session one set of 24 items was presented visually and another set was presented aurally, with a 90 sec break between sets. The sets were randomly chosen for each $S$ with the restriction that all elght sets be used over the four days. The first set that half the Ss received each day was presented visually and the second set aurally. The remaining Ss received the auditory set first each day and the visual set second.

The basic procedure was that used by Peterson \& Peterson (1959). Four retention intervals, 0, 3, 6, and $18 \mathrm{sec}$, were studied. Each particular interval appeared once in each successive block of four trigrams, with the intrablock position being randomly determined for each S. Immediately following each trigram, a 


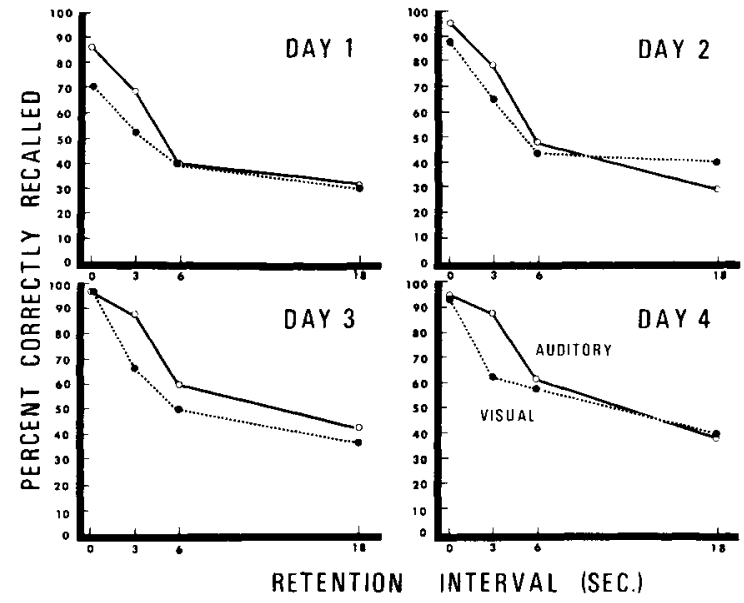

Fig. 1. Percentage of trigrams correctly recalled on each of four consecutive days as a function of retention interval and mode of presentation.

three-digit number, from which Ss were to count backwards by $3 \mathrm{~s}$ (or $4 \mathrm{~s}$ ) during the retention interval, was presented for 1 sec. The number was presented visually on the memory drum for visually presented trigrams and was read aloud for aurally presented trigrams. A different number was presented after each trigram. A small light in front of S signalled the end of the retention interval. As soon as the light came on, $S$ was to try to recall the trigram which had just been presented. The light remained on for $15 \mathrm{sec}$, the duration of the recall period.

\section{Results}

The mean percentage of trigrams correctly recalled on each of the four days is shown in Fig. 1 as a function of retention interval and mode of presentation. In general, performance improved over days for both modes of presentation. In addition, as Fig. 1 shows, recall tended to be better under auditory presentation for short retention intervals, but the difference between auditory and visual presentation decreased as the retention interval lengthened. In fact, on Day 2 recall following the $18 \mathrm{sec}$ retention interval was significantly better under visual presentation than under auditory.

To test the overall significance of these effects, an analysis of variance based on the "cross-over" design (Cochran \& Cox, 1957, pp. 127-133) was performed on the data. Results of the analysis showed that the interaction described above, between retention interval and mode of presentation, was significant $(F=3.60, d f=3 / 192, p<.025)$. The main effects of mode of presentation ( $F=9.93, \mathrm{df}=1 / 56, \mathrm{p}<.005$ ) and retention interval $(F=11.63, \mathrm{df}=3 / 192, \mathrm{p}<.0005)$ were also significant. The only other significant effect was due to days $(F=9.71$, df $=3 / 56, p<.0005)$. Discussion

Since results of this study show the same general trends as those obtained by both Murdock (1966) and Schulz \& Hopkins (in press), it seems unlikely that the effects they observed were due to intralist interference. It may be that the modality effects reflect characteristically different ways of processing and storing visual and auditory information. Nevertheless, other kinds of interference may still play a large role. For example, if all "permanent" information storage is auditory, then aurally presented information which enters the AIS directly must be subjected to massive amounts of proactive interference (PI) which could produce a rapid loss of information over time, particularly when rehearsal of the information to keep it at "full strength" is prevented. Visually presented information, on the other hand, would notbe subject to as much PI. At least some of it would be "protected" from PI by being held as unanalyzed information in the VIS, particularly when rehearsal (the mechanism by which information is transferred from the VIS to the AIS) is prevented. The net effect of these factors would be to produce better immediate recall of auditory information (because it is more easily encoded in the AIS), with either better recall of visual information, or no difference between the two, over longer intervals of time.

References

COCHRAN, W. G., \& COX, GERTRUDE, M. Experimental designs. New York: Wiley, 1957

CONRAD, R. Acoustic confusions in immediate memory. Brit. J. Psychol, 1964, 55, 75-84.

MURDOCK, B. B., Jr. Visual and auditory stores in short-term memory. Quart. J. exp. Psychol., 1966, 18, 206-211.

PETERSON, L. R., \& PETERSON, MARGARET J. Short-term retention of individual verbal items. J. exp. Psychol., 1959, 58, 193-198.

SCHULZ, R. W., \& HOPKINS, R. H. Presentation mode and meaningfulness as variables in several verbal-learning tasks. J. verbal Learn. verbal Behav., in press.

SPERLING, G. A model for visual memory tasks. Hum. Factors, 1963. 5, 19-36.

TURVEY, M. T. The effects of relıearsing analyzed information upon the retrieval of unanalyzed information. Psychon. Sci., 1966, 6, 365-366.

WICKELGREN, W. A. Acoustic similarity and intrusion errors in shortterm memory. J. exp. Psychol., 1965, 70, 102-108. Note

1. This research was supported by Grant APB-86 from the National Research Council of Canada to the second author. We are grateful to Miss Audrey Kirby and Miss Peggy Sheffer for their assistance in running Ss. 